\title{
Mobile family learning in the science museum
}

\author{
Wijitra Suriyakul Na Ayudhya ${ }^{1,2}$ \\ wijitra@nsm.or.th \\ Giasemi Vavoula ${ }^{1}$ \\ ${ }^{1}$ University of Leicester, United Kingdom \\ ${ }^{2}$ National Science Museum, Thailand
}

\begin{abstract}
This paper presents the development and evaluation of a mobile app for families visiting a science museum in Thailand. The app was designed to help adults in family groups to support children's learning during the visit while learning about new science concepts and ideas themselves. The design of the app was based on a family learning needs analysis study. The evaluation focused on the impacts of the app on family learning outcomes and on family engagement with exhibits. Findings suggest that the app (a) significantly increased family dwell time, (b) provided an additional platform for family interactions, and (c) amplified learning outcomes.
\end{abstract}

\section{CCS CONCEPTS}

- Human-centered computing $\rightarrow$ Ubiquitous and mobile computing design and evaluation methods

\section{KEYWORDS}

Family learning; mobile learning; science museum

\section{ACM Reference format:}

Wijitra Suriyakul Na Ayudhya and Giasemi Vavoula. 2017. Mobile family learning in the science museum. In Proceedings of mLearn, Larnaca, Cyprus, October 2017 (mLearn), 9 pages.

DOI: $10.1145 / 3136907.3136948$

\section{INTRODUCTION}

Despite intense research interest in the use of mobile technologies to support museum visits [1, 2-10], little research in mobile learning has focused on family groups. The family is a museum visitor group with particular characteristics, including a shared history of interactions that underlie both the visit agenda and the learning frameworks of individual family members. One of the main characteristic of mobile learning technology is that it is personal [11], hence its use by a family group who value the 'shared-ness' of their visit presents an interesting case. It is therefore important to understand how the introduction of technology that is primarily personal might impact an experience

Permission to make digital or hard copies of all or part of this work for personal or classroom use is granted without fee provided that copies are not made or distributed for profit or commercial advantage and that copies bear this notice and the full citation on the first page. Copyrights for components of this work owned by others than the author(s) must be honored. Abstracting with credit is permitted. To copy otherwise, or republish, to post on servers or to redistribute to lists, requires prior that is valued for its intra-group interactions. Families in the science museum in particular want experiences that are hands-on, allow multiple users and multiple entry points, facilitate family interactions, and enable parents to facilitate the children's learning while learning themselves [1, 4, 12-24].

This paper presents research on the impact of mobile technology on the family visit to the science museum. The word impact is used as a general term that captures changes in the ways that families engage with and learn from the museum visit changes that result from the integration of mobile technologies within the family experience. Through a case study of developing and evaluating mobile tools for families in the National Science Museum (NSM), Thailand, this research examines what these impacts are and why they occur.

Section 2 of this paper presents a brief literature review of family learning in museums, and Section 3 outlines a family needs analysis study conducted at the NSM at the start of this project. Section 4 presents the mobile app for families visiting the NSM that was designed based on the family needs analysis and informed by constructivist, discovery [25] and socio-cultural learning theories [26]. Section 5 presents an evaluation of the impacts of the app on the family experience, in particular how use of the app affects family behaviours and engagement in the museum and impacts family learning outcomes. Section 6 concludes the paper with a discussion of the evaluation findings and suggestions for future research and development in this area.

\section{FAMILY LEARNING IN MUSEUMS}

Dierking et al. define family learning as the "process that incorporates the social bonds between relatives and the family's experience with objects, ideas and situations, becoming in essence, the family narrative" [18]. Families use museums as places in which they can play, talk and learn from each other, and develop knowledge as they engage in family activities [20].

Family learning in the museum is a social activity. The family group works together to construct a communicative experience with the museum $[18,24]$ that involves coordination of activity and responsiveness. Each family brings to the museum their unique culture, shared and individual knowledge, experiences, and expectations $[14,27,20]$. The interactions between adults and

specific permission and/or a fee. Request permissions from permissions@acm.org. mLearn, Larnaca, Cyprus

(c) 2017 Copyright held by the owner/author(s). Publication rights licensed to ACM. 978-1-4503-5255-0...\$15.00

DOI: $10.1145 / 3136907.3136948$ 
children in family groups vary from playful to very didactic [14, 17]. Families learn in the museum by acquiring, distributing, transferring and relating exhibit information with their prior experiences [17, 23]. Variations in verbal and nonverbal patterns of learning behaviour among family members have been described [14, 17, 24]. For example, adults in family groups usually read text panels, explain and demonstrate to the children; while children prefer to interact with the exhibits. Adults tend to modify their behaviour to suit the needs of the children [24]. Family groups have longer conversations and spend more time at the exhibits than groups without children [16].

The family learning experience is instigated by their social interactions during the visit, and lasts long after the visit [14, 28]. Discussions among family members about the museum experience does not only occur at the moment of experiencing an exhibition, but can take place any time in the days, weeks, or even months after the museum experience [14, 27, 28, 29].

Families have agendas for their museum visits [23, 24, 30-32] which directly influence family learning in the museum [20]. Visiting a museum is a free choice activity for families, therefore the motives and objectives of a family visit are crucial factors that shape family learning. Family motives can vary from entertainment to convenience to family traditions, but can motivate family learning equally effectively [12].

Research on family learning has highlighted the effectiveness of hands-on exhibits in supporting family learning. Borun et al. [15] proposed seven exhibit characteristics that support learning by multi-age groups such as families: Multi-sided, Multi-user, Accessible, Multi-outcome, Multi-modal, Readable and Relevant. Henderson et al. [33] developed an interactive gallery for children and families called 'ArtQuest' where a family group can share and interact together, with opportunities to touch and examine objects, documents, and other materials that facilitate the family's understanding of the museum topic.

Dierking et al. [18] argue that technology-based experiences in exhibitions can encourage and facilitate social interaction. Mobile technologies resonate with the characteristics of the museum environment and the visitor experience [34]. However, our understanding of how families benefit from the use of technology in museums is limited [18].

\section{National Science Museum Thailand: Family Needs Analysis}

A family learning needs analysis was conducted at the NSM in September 2012. Six museum staff (exhibition developers, educators and gallery facilitators) and nine family groups comprising at least one adult and one or more children were interviewed. The families said that they visited the NSM to spend leisure time together, have fun, and acquire knowledge about science and technology. They recognised the value of the science museum as an out-of-school science learning setting that can also entertain children. The adults and the children in a family had sometimes competing interests as to which route to take and which exhibits to engage with. Adults let the children make these choices and assumed a supportive role, by reading text panels and relaying the information to the children who were meanwhile engaging with the interactive exhibits. The families discussed the exhibits they engaged with, but adults' learning depended on the availability of uncomplicated information in the gallery.

One obstacle to family learning was the disconnect between the hands-on experience at the interactive exhibits and the information available in the exhibit's interpretation panels. This disconnect is a result of unclear / complicated language that is used in the interpretive panels, understanding of which often depends on the science literacy level and educational background of the visitors. Thus, although an interactive exhibit may be very popular and easy to interact with (e.g. the Plasma Ball), families may still not learn why the scientific phenomenon that the exhibit demonstrates matters and which of its applications they may have encountered in their everyday life. Unclear or limited instructions for exhibits that are more complicated to operate or where the scientific phenomena are not directly observable (e.g. the Whisper Dishes), can leave families unsure whether the exhibit is out-oforder or they are doing something wrong. Families overcome these difficulties by mimicking the interactions of other visitors.

The family needs analysis pointed clearly to the need for mobile tools that support family interactions with exhibits and understanding of the scientific phenomena that occur through these interactions. These tools need to use simple language and provide more examples and content to help families to connect the science behind the exhibits to everyday life and activities.

Despite the above problems, families did enjoy interacting with the exhibits and did not appear deterred by the learning difficulties. The predominance of leisure and fun in the family visit agenda can explain this: enjoying the company of each other while pursuing a leisure activity predisposes families to enjoy a spectacular interactive exhibit such as the Plasma ball, even if the opportunity to learn about the science of Plasma is missed. A key consideration in designing mobile tools for family learning in the science museum is therefore to ensure that their use can blend into the family experience in a way that does not distort these main characteristics of the family visit: social, enjoyable, shared.

\section{Museums Pools: The Science Museum App}

The Museums Pools app was designed by the NSM and developed for Android and iOS in collaboration with the National Electronics and Computer Technology Centre, Thailand. The app covers the Science Museum, the Information Technology Museum, and the Chaosamphraya National Museum. In this paper, we focus on Museums Pools' use in the Science Museum.

The app allows visitors to plan their visit through accessing general information about the museum (opening times, admission fees etc.); the museum's news and events calendar, including information about temporary exhibitions and special activities scheduled for families; a map with travel directions to the museum; and information about Highlight Exhibits (the nine most attractive exhibits) through short descriptions and related images.

Inside the museum, once the visitor has connected to the museum's WiFi, the map function displays the museum's three floor plans with Highlight Exhibits and other prominent points 
clearly marked, to help users navigate the galleries. Visitors can either select a Highlight Exhibit that they wish to view and get directions to find it along with content; or if they approach an exhibit without help from the navigation function, they can scan the its QR code to access the related content directly. The exhibit content that is available through the WiFi goes beyond the short descriptions that visitors can access before the visit, to include multimedia (pictures, text, video, animations, audio narrations) with extended scientific information, instructions how to use the interactive exhibits, and explanations of the science on display.

To raise awareness about the availability of the app and to support visitors in setting up their devices, museum staff, instruction panels and information leaflets are available at a support desk near the entrance. Visitor this can find out what the app does, how it works, how to download, install and use it.

A WordPress-based back-end portal accompanies the app, through which authorized museum staff can upload new / edited exhibit content, update the museum's news and events calendar, and add more Highlight Exhibits.

\section{Evaluation}

\subsection{Methods}

We evaluated the Museums Pools app with 84 families at the NSM in April 2015 (see Table 1). The families were assigned into one of five groups (A to E) depending on which weekend they were visiting. Only families in groups A, C and E used the app. These families tended to download the app on a mobile device and designate one family member as the app main user - typically an adult, although in some families the main user was a child. The usability and learning outcomes interviews sought input from the whole family group, therefore families were given the opportunity to deliberate and give answers that all family members agreed on. Thus, if for example a family's response to a question was 'strongly disagree', this answer represents the view of the whole family group.

Table 1: Number of Families per Data Collection Activity

\begin{tabular}{cccccc}
\hline & \multicolumn{3}{c}{ Usability questions } & Learning & $\begin{array}{c}\text { Video- } \\
\text { based } \\
\text { Group }\end{array}$ \\
\cline { 3 - 5 } outcomes & SUS & $\begin{array}{c}\text { Generic } \\
\text { usability }\end{array}$ & $\begin{array}{c}\text { Generic } \\
\text { visit }\end{array}$ & $\begin{array}{c}\text { interview } \\
\text { observation }\end{array}$ \\
\hline $\mathrm{A}(26)$ & $\mathrm{x}$ & $\mathrm{x}$ & $\mathrm{x}$ & & \\
\hline $\mathrm{B}(17)$ & & & $\mathrm{x}$ & $\mathrm{x}$ & \\
\hline $\mathrm{D}(21)$ & & $\mathrm{x}$ & $\mathrm{x}$ & $\mathrm{x}$ & \\
\hline $\mathrm{E}(10)$ & & & & & $\mathrm{x}$ \\
\hline
\end{tabular}

*Groups A, C and E used the Science Museum app during their visit whereas groups B and D did not use the app.

Usability interviews: Families in group A were asked to complete a System Usability Scale (SUS) questionnaire [35], the ten Likert-style questions of which were modified to better reflect use of a mobile app. After the visit, families in groups A and C were asked open-ended questions regarding perceived advantages and problems with the app. Finally, families in groups A, B and C were asked open-ended questions regarding what facilitated their learning, what general problems they faced in the museum, and what the museum can do to improve its service to families.

Learning Outcomes: Families in groups B and C took part in a pre-visit and a post-visit interview that focused on learning outcomes. The Generic Learning Outcomes (GLOs) [36] framework guided the design of these questions, which sought evidence under the framework's five outcome categories: knowledge and understanding; skills; enjoyment and creativity; attitudes and values (referring to changes in attitudes towards science and the museum); and action, behavior and progression (referring to resolutions to change future science learning behaviour and/or using science to inform everyday life decisions and practices). Questions related to prior visitation and visit motives were also asked.

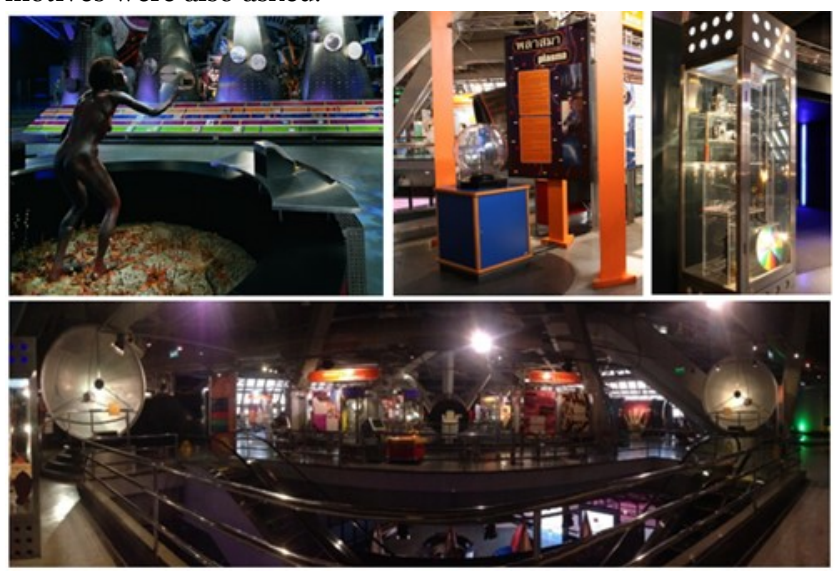

Figure 1: Lucy (top left), Plasma Ball (top middle), Camera (top right), and Whisper Dishes (bottom)

Questions regarding knowledge and understanding focused on four exhibits, which were specifically chosen to represent different interpretation and science communication methods (Fig. 1). "Lucy" is a model reconstruction inspired by the remains of the human ancestor Australopithecus Afarensis and is popular with visitors. Its audio interpretation is often difficult to hear because of audio from nearby exhibits and visitor noise. The "Whisper Dishes" demonstrate the reflection of sound waves and, although a popular exhibit, visitors frequently comment that the instructions for using it are not simple and clear enough, and that the phenomena it demonstrates are difficult to perceive and understand. The "Plasma Ball" attracts many visitors who spend a long time interacting with and taking pictures of it. However, it can only accommodate up to 4-5 people at a time so queues form around it frequently. "Camera" is a display cabinet of objects that make use of the properties of light and is one of the least popular exhibits, mainly because of the very limited information it gives and the lack of opportunities for interaction with its objects.

The Learning Outcomes interviews applied the principles of Personal Meaning Mapping (PMM) [32] to capture changes in knowledge and understanding. Instead of PMM's mind map drawings before and after the visit, we asked families to talk about 
their understanding of the four exhibits' science before and after the visit. A marking scheme was then applied to family responses, assigning a mark from 0 to 3 depending on the level of detail included in the family response $(0=$ Know nothing about the exhibit; 1 = Can describe the exhibit but not explain it; 2 = Can describe the exhibit and partially explain it; $3=$ Can describe and fully explain the exhibit). For example, family \#18 in group $\mathrm{C}$ was assigned a mark of 1 for their pre-visit description of the Plasma Ball, "It is a glass globe with a sparkly blue lightning inside"; and a mark of 3 for their post-visit description of the same exhibit, "Plasma is the fourth state of matter. Inside the globe, there is an inert gas stimulated by electricity to create the plasma state. The plasma light looks similar to the light of lightning and it contains a lot of positive and negative charge in the ball."

Answers to questions related to the other four GLOs from group B and group C families were coded following Grounded Theory [37]. This enabled us to identify common themes across the two groups and to make comparisons between the frequencies with which themes appeared in the two groups' responses.

Family Engagement: Video recordings from a CCTV camera located above the Plasma Ball exhibit captured the interactions of families in groups D and E (Fig. 2). The recordings captured family behaviours and states of engagement. Each family video was watched several times, noting down the sequence of each family member's activities and their duration. Observed activities of a similar nature were then coded into 18 distinct action categories, four of which related to the use of the mobile app and were therefore only observed in group E. Evidence of the other 14 distinct actions was found in both groups.

These distinct actions were then matched against Bitgood's [38] three stages of engagement: capture, focus and engage. Some actions naturally fitted one of these stages. For example, when a visitor approaches an exhibit, it is obvious that it has for some reason captured their attention. Similarly, when a family member calls another family member to come to see the exhibit, it is obvious that they are capturing that family member's attention. The action 'play with ball' (instances of family members manipulating and/or experimenting with the Plasma Ball alone or in the presence of other family members) was observed both as the first thing a visitor does when he or she approaches the exhibit, whereupon it could be classified as 'focus'; and as something done after having read a panel, or watched other visitors interacting with it, whereupon it could be classified as 'engage'. Bitgood's inclusion of 'touch object briefly' under the 'focus' category prompted us to differentiate between short and long instances of 'play with ball'. More specifically, we noticed that the duration of this action ranged considerably, both among visitors and among different instances where the same visitor did this action a number of times. This was an indication that perhaps the same action can be an instance of 'focus' or of 'engage' at different times, for different visitors. In addition, children played with the ball nearly twice as many times as adults did, and did so for longer periods of time. The following algorithm was thus used to characterize an instance of 'play with ball' as focused attention or engagement for adults and children: if the instance lasted for less than the median duration of this action across all 4 adults/children, then it was characterized as 'focus'; if it lasted the same as or more than the median, then it was 'engage'.

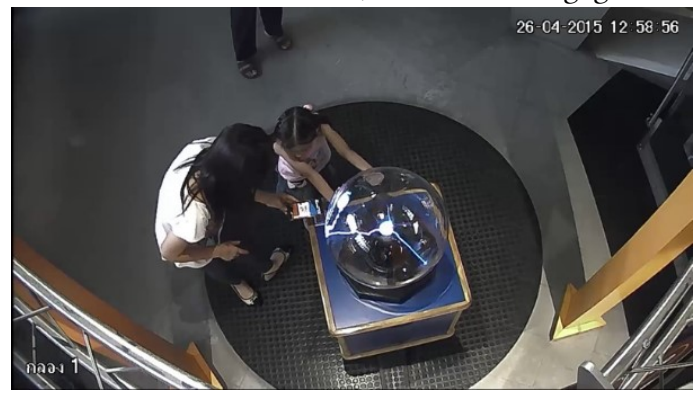

Figure 2: CCTV frame of Group E family interacting with the Plasma Ball

Table 2: Coding and Median Durations of Observed Actions

\begin{tabular}{|l|l|l|l|l|l|}
\hline & & \multicolumn{3}{|l|}{ Group B } & \multicolumn{2}{l|}{ Group C } \\
\hline Action & Coding & A & C & A & C \\
\hline approach & capture & 1 & 1 & 1 & 1 \\
\hline play with ball & focus/engage & 13 & 19.5 & 10 & 17.5 \\
\hline motion & distract & 16.5 & 9 & 2 & 2 \\
\hline $\begin{array}{l}\text { encourage } \\
\text { participation }\end{array}$ & capture & 1 & & 4 & 1.5 \\
\hline move away & disengage & & & & \\
\hline pull others away & disengage & & 0.5 & 10 & 2 \\
\hline read panel & engage & 16 & 7 & 10 & 2 \\
\hline point and tell & engage together & 17 & & 10 & 2 \\
\hline watch/ listen & focus & & 17 & 7 & 4 \\
\hline read out loud & engage together & 9 & & 9 & 4 \\
\hline take photo /video & distract & 16 & & 25 & 10 \\
\hline talk with family & engage together & 12 & 9 & 20 & 15 \\
\hline $\begin{array}{l}\text { move around } \\
\text { exhibit }\end{array}$ & capture & & & & \\
\hline linger not engaged & distract & 7 & 18 & 7 & 4 \\
\hline scan QR code & focus & - & - & 6 & 7 \\
\hline prepare to use app & focus & - & - & 14 & 10 \\
\hline $\begin{array}{l}\text { watch/listen app } \\
\text { media }\end{array}$ & engage & - & - & & \\
\hline use app together & engage together & - & - & 27 & 6 \\
\hline
\end{tabular}

Three of the distinct actions could not easily fit within Bitgood's capture-focus-engage framework. These were 'motion' (bodily movement indicates that the person's attention has been disrupted), 'take photo/video', and 'linger not engaged' (the person remains in the vicinity of the exhibit but does not pay attention to it). A 'distract' category was added to account for these behaviors. Furthermore, some behaviours always involved at least one other family member. For example, when one family member was reading out loud a text panel, other family members were 'watching/listening'. These instances were coded as 'engage together'. Finally, the actions of moving away from the exhibit and pulling other family members to move away too were coded as 'disengage'. Table 2 shows the coding and median durations of 
observed actions for adults (A) and children (C).

\subsection{Findings}

5.2.1 Usability. Group A gave the app a SUS score of 73.8, placing it firmly within the acceptable range of perceived usability [39]. Group A and C families identified the main advantages of the app as: gaining additional scientific content, instructions how to use the interactive exhibits, and information about the Science Museum (79\%); post-visit access to content (55\%); and support to engage more with exhibits in the galleries (34\%). A large proportion of families (40\%) indicated no problems with using the app. The rest reported problems related to difficulties with connecting to the museum's WiFi (23\%) and the inaudibility of app audio in certain (noisy) areas of the museum (15\%). Less frequently reported were app crashes (11\%) (later resolved with a bug fix), issues with QR code scanning (6\%) and difficulties with learning to use the app (4\%). It is unclear whether the learnability issues concerned the interface of the app itself or the use of $Q R$ codes; however, the low frequency of this problem indicates that the app is generally easy to use for the majority of family visitors - a finding corroborated by the SUS score.

Table 3: What helped learning, problems and needs

\begin{tabular}{|c|c|c|c|}
\hline & & $\begin{array}{l}\text { Groups A, C } \\
\text { (app users) }\end{array}$ & $\begin{array}{l}\text { Group B } \\
\text { (non-users) }\end{array}$ \\
\hline \multirow{7}{*}{ 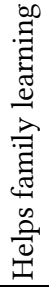 } & Interactive exhibits & $64 \%$ & $88 \%$ \\
\hline & Family interactions & $60 \%$ & $47 \%$ \\
\hline & Museum facilitators & $11 \%$ & $35 \%$ \\
\hline & Mobile app & $62 \%$ & $\mathrm{~N} / \mathrm{A}$ \\
\hline & Pre-visit info & $2 \%$ & $12 \%$ \\
\hline & Text panels & $9 \%$ & $6 \%$ \\
\hline & Special events/activities & $\mathrm{N} / \mathrm{A}$ & $18 \%$ \\
\hline \multirow{5}{*}{$\begin{array}{l}\frac{a}{0} \\
\frac{0}{0} \\
0 \\
0 \\
0\end{array}$} & Lack of facilitators & $9 \%$ & $29 \%$ \\
\hline & Lack of information & $9 \%$ & $24 \%$ \\
\hline & Broken exhibits & $19 \%$ & $24 \%$ \\
\hline & Crowded exhibits & $9 \%$ & $12 \%$ \\
\hline & High noise levels & $6 \%$ & $6 \%$ \\
\hline \multirow{7}{*}{ 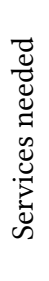 } & More facilitators & $6 \%$ & $35 \%$ \\
\hline & Exhibit maintenance & $19 \%$ & $6 \%$ \\
\hline & More activities & $13 \%$ & $6 \%$ \\
\hline & Better advertising & $15 \%$ & $6 \%$ \\
\hline & Restaurants/shops & $13 \%$ & $12 \%$ \\
\hline & Public transport & $9 \%$ & $6 \%$ \\
\hline & Extended coverage & $34 \%$ & $\mathrm{~N} / \mathrm{A}$ \\
\hline
\end{tabular}

Table 3 shows what families found helpful for their learning in the museum, what general problems they had, and what additional services could further support and enhance their learning. Families who used the app (groups A and C) were as highly likely to mention the app as the interactive exhibits and interactions with family members among the things that helped their learning, while their most frequently mentioned problem were broken interactive exhibits and the most frequently mentioned additional service was extending the app to cover more museum exhibits followed by exhibit maintenance. Families who did not use the app (group B) were much more likely than app users to mention the interactive exhibits, museum facilitators and special events/activities, but less likely to mention family interactions as aids to their learning. These families reported problems related to the lack of facilitators, the lack of information and broken exhibits more frequently than families who used the app, and the main additional service they requested was the availability of more facilitators.

5.2.2 Learning Outcomes. We looked at families' motivations for visiting the museum to establish the extent to which learning was a central objective of the family visit. Group C (app users) were more likely than group B (non-users) to cite entertaining the children and relaxing as reasons for visiting (90\% and $81 \%$ versus $75 \%$ and $75 \%$ respectively). By contrast, group B were more likely to cite children's science learning than group C (38\% versus $25 \%$ ). It appears that the visit agendas of families who consented to take part in the app trial were more likely to be entertainment-driven, while the visit agendas of families who consented to take part in the non-app trial were more likely to be learning-driven.

Table 4: Pre- and post-visit scores for knowledge and understanding

\begin{tabular}{|l|l|l|l|}
\hline & & \multicolumn{2}{|l|}{ Average score } \\
\hline \multirow{4}{*}{ Lucy } & & Group B & Group C \\
\cline { 2 - 4 } & Pre-visit & 0.47 & 0.62 \\
\cline { 2 - 4 } & Post-visit & 1.47 & 1.81 \\
\cline { 2 - 4 } & Difference & +1.00 & +1.19 \\
\hline \multirow{3}{*}{ Whishes } & Pre-visit & 0.59 & 0.52 \\
\cline { 2 - 4 } & Post-visit & 1.24 & 1.81 \\
\cline { 2 - 4 } & Difference & +0.65 & +1.29 \\
\hline Plasma Ball & Pre-visit & 0.47 & 0.62 \\
\cline { 2 - 4 } & Post-visit & 1.59 & 1.86 \\
\cline { 2 - 4 } & Difference & +1.12 & +1.24 \\
\hline
\end{tabular}

Knowledge and Understanding. On average, families in both groups $\mathrm{B}$ and $\mathrm{C}$ scored higher for knowledge and understanding after the visit compared to their pre-visit average scores for three out of the four exhibits, with group $\mathrm{C}$ outperforming group $\mathrm{A}$ in all three post-tests (see Table 4). A Mann-Whitney U-test between groups' B and C test score differences shows statistical significance for the Whisper Dishes exhibit $(\mathrm{z}=2.73, \mathrm{p}=0.063<0.5)$ but no statistical significance for the other two exhibits. There was no improvement for either group B or group C for the Camera exhibit.

Skills. Families in the two groups identified similar skills that they developed during their visits, all related to ways of learning and communicating about science (see table 5). Manipulating the interactive exhibits was a skill reported by all families. Group C were more likely to report skills related to learning about science through talking about the exhibits and reading the text panels than group B. A large percentage (86\%) of group C families also reported the skill of using the app to support their learning. 
Table 5: Science learning skills developed during visit

\begin{tabular}{|l|l|l|}
\hline & Group B & Group C \\
\hline Manipulate exhibit & $100 \%$ & $100 \%$ \\
\hline Talk about exhibit & $75 \%$ & $86 \%$ \\
\hline Multimedia/shows & $82 \%$ & $81 \%$ \\
\hline Text panels & $65 \%$ & $86 \%$ \\
\hline Special activities & $6 \%$ & $0 \%$ \\
\hline Use app & N/A & $86 \%$ \\
\hline
\end{tabular}

Attitudes and values. Here we examine changes in family perceptions and opinions about science as a subject and about the science museum. The broad categories of attitude change reported by both groups were similar (Table 6).

Table 6: Categories of attitude change reported by families

\begin{tabular}{|l|l|l|}
\hline & Group B & Group C \\
\hline $\begin{array}{l}\text { Visit makes science easier to } \\
\text { understand/engage with through play }\end{array}$ & $53 \%$ & $67 \%$ \\
\hline Science here is more fun than at school & $47 \%$ & $24 \%$ \\
\hline More interested in science & $18 \%$ & $71 \%$ \\
\hline Want to do more scientificexperiments & $12 \%$ & $10 \%$ \\
\hline
\end{tabular}

A larger percentage of group C than group B said that the visit made science easier to understand and to engage with through play (67\% versus 53\%). There was also a staggering difference between the percentages of group B and group C who said they were more interested in science after the visit $(18 \%$ and $71 \%$ respectively). In contrast, a larger percentage of group B (47\%) than group C (24\%) said that they found science more fun at the museum than in school. Only a small percentage of families in both groups said that they would be engaging in scientific experiments as a result of their visit.

Table 7: Positive and negative perceptions of the museum

\begin{tabular}{|l|l|l|l|}
\hline & & Group B & Group C \\
\hline \multirow{4}{*}{} & Good leisure destination & $35 \%$ & $76 \%$ \\
\cline { 2 - 4 } & Good informal learning environment & $47 \%$ & $86 \%$ \\
\cline { 2 - 4 } & Feel positive about the museum & $59 \%$ & $90 \%$ \\
\cline { 2 - 4 } & Modern design & N/A & $43 \%$ \\
\cline { 2 - 4 } & More museums like this & N/A & $29 \%$ \\
\hline \multirow{2}{*}{} & More facilitators needed & $41 \%$ & $29 \%$ \\
\cline { 2 - 4 } & Broken exhibits & $18 \%$ & $38 \%$ \\
\cline { 2 - 4 } & Museum too far from city & $12 \%$ & $14 \%$ \\
\hline
\end{tabular}

Group B families mentioned on average one positive and one negative perception about the museum after their visit, while group $\mathrm{C}$ families mentioned on average three positive and one negative things. The two groups mentioned similar positive and negative things (Table 7). Group $\mathrm{C}$ families were almost twice as likely as group B to say that after the visit they found the museum to be a good leisure destination and a good informal learning environment, and they have positive feelings about the museum. Significant percentages of group C also appreciated the museum's
/ galleries' modern design or said they would like more museums like this. Group B were more likely to make negative comments about the low number of facilitators, while group $\mathrm{C}$ were more likely to make negative comments about broken exhibits.

Enjoyment. Families in both groups were equally highly likely to say they enjoyed the interactive exhibits ( $82 \%$ group B and $86 \%$ group C). A small percentage (6\%) of group B said they enjoyed the museum activities they took part in, while $10 \%$ of group $\mathrm{C}$ said they enjoyed using the app. One in ten families in both groups said they enjoyed everything about their visit.

Action, Behaviour and Progression. Nearly all families in both groups (94\% group B and $100 \%$ group C) resolved to talk about their visit with friends and family. Families in group $\mathrm{C}$ were more likely than group B to report that the visit gave them confidence to learn and enquire more about science (90\% vs 59\%) and that they would be making connections with past and future science learning experiences ( $71 \%$ vs $41 \%$ ). Finally, $67 \%$ of group C resolved to use the app after their visit.

Family behaviour in the gallery. As well as data on learning outcomes, the post-visit interviews asked groups B and C about their activity in the gallery. The families talked about the construction of their visit itinerary (Table 8), with only a small percentage of families saying that it was the adults who led the itinerary. Children in group B were twice as likely as children in group $\mathrm{C}$ to lead. In $81 \%$ group $\mathrm{C}$ families, adults and children shared ownership of the visit itinerary, either by constructing it by consensus or by viewing exhibits independently of each other. The same was true for $53 \%$ of group B families.

Table 8: Construction of the family itinerary in the museum

\begin{tabular}{|l|l|l|}
\hline Visit itinerary led by & GroupB & GroupC \\
\hline Adults & $6 \%$ & - \\
\hline Child/ren & $41 \%$ & $19 \%$ \\
\hline Consensus & $24 \%$ & $38 \%$ \\
\hline Each family member leads their own & $29 \%$ & $43 \%$ \\
\hline
\end{tabular}

Families also talked about the activities they did in the gallery (Table 9). Interacting with the exhibits and supporting children to read the text panels and find out information about the exhibits were reported similarly by families in both groups.

Differences in the frequencies that other activities were reported by the two groups paint an interesting picture for the impact of the app on family behavior in the gallery. Group C families were more likely to say that they engaged in inquiry and discussion about the exhibits and that the adults provided the children with explanations about the science, while being almost $50 \%$ less likely to say that the children focused on playing with the exhibits uninterested in learning about science. It appears that the presence of the app gave more adults the confidence to play the role of 'explainer' and encouraged more families to engage in exhibit-focused discussion while making the science content less alienating for the young family members.

Group C families also described how they used the app, with watching video content most commonly reported, followed by 
reading the textual information in the app and listening to audio content.

Table 9: Family activities in the museum

\begin{tabular}{|l|l|l|}
\hline & Group B & Group C \\
\hline Enquiry and discussion about exhibits & $82 \%$ & $95 \%$ \\
\hline $\begin{array}{l}\text { Adults support children to read text } \\
\text { panels / find info }\end{array}$ & $76 \%$ & $71 \%$ \\
\hline Interact with exhibits & $100 \%$ & $100 \%$ \\
\hline Adults explain info to children & $12 \%$ & $29 \%$ \\
\hline Children play, uninterested in learning & $53 \%$ & $5 \%$ \\
\hline Use app - video content & N/A & $86 \%$ \\
\hline Use app - audio content & N/A & $38 \%$ \\
\hline Use app - text content & N/A & $62 \%$ \\
\hline Photo taking & $12 \%$ & $43 \%$ \\
\hline
\end{tabular}

5.2.3 Family engagement. The video-based observations showed that app users (group E) spent on average a longer time at the Plasma Ball exhibit than non-users (group D). If we define 'Family Dwell Time' as the time between the arrival of the first family member at the exhibit and the departure of the last family member from the exhibit, then the average Family Dwell Times for the control and the experimental groups were 82.2 and 180 seconds respectively. A two-sample t-Test on control and experimental family dwell times indicates that the difference between the two groups was statistically significant $(t=3.07, p=0.007<0.01)$.

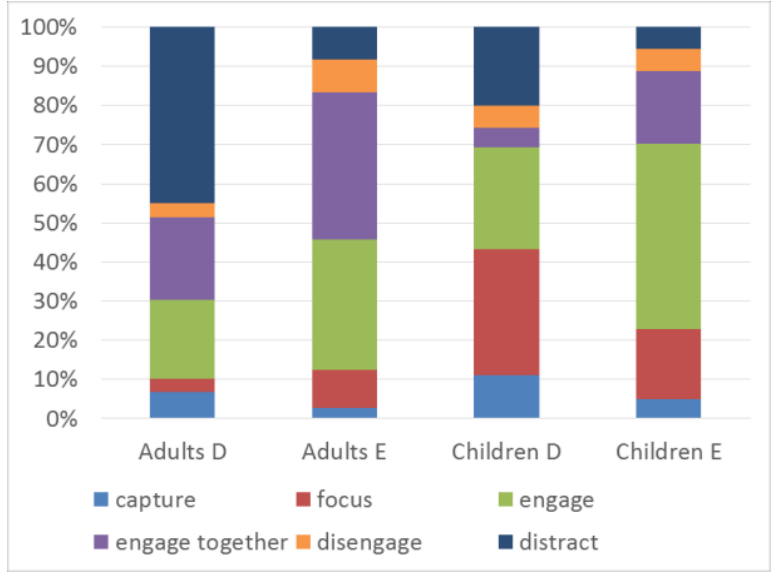

Figure 3: average percentage of average dwell time on different stages of engagement for adults and children in groups $\mathrm{D}$ and $\mathrm{E}$

For each family in each of the two groups we calculated the average time that adults and children spent in each state of engagement and the average dwell times for adults and children. We were then able to calculate the percentage of adult and children dwell time in each family that was spent in each state of engagement. Figure 3 presents averages of these percentages for adults and children in families in the two groups. As can be seen in the graph, both children and adults in group E (app users) spent much larger proportions of their dwell time engaging alone or with other members of the family than their group D (non-users) counterparts. They also spent on average much smaller proportions of their dwell time distracted/disengaged. Adults in groups D and E seem to spend comparable proportions of their dwell time on capture and focus states. By contrast, group E children spent almost half proportion of their dwell on capture / focus compared with group D children, suggesting that group E children's attention was engaged more quickly than group D.

\section{Discussion and concluding remarks}

The value of interactions for the family. Family members valued interactions with each other. The family visit is primarily a social experience. Families in this study showed clearly this to be the case, placing their 'togetherness' higher on their visit agendas than science learning. The app has successfully amplified these types of interactions. By directly referencing the interactive exhibits, offering visitors instructions and guidance how to use them and assisting them to interpret the outcomes of their interactions with the exhibits, the app has intensified the visitors' use of the exhibits. At the same time, the app was something to talk about: it became the focus of joint family attention when family members come together to watch a video or demonstration, or listen to a narrated story. But it also became a tool for families to interact with each other meaningfully, by empowering parents to explain the museum to their children.

Attitudes towards science and the science museum. Integration of the app in the family experience resulted in increased interest in science. The scientific content and media in the app made science more interesting and less alienating, and arose curiosity and interest, as app users appear to leave the museum with the intention to use the app again, thus indicating an intention to construct a science learning experience to follow up their visit. Key to this seem to be the multimedia content and simple yet scientific language of the app.

In this study, families regarded the science museum as a place for them to spend leisure time together, while providing a good environment for informal science learning - much like other museums [12]. By making science seem more accessible and easier to understand within family leisure time, the app develops positive attitudes towards science.

Family behaviours at exhibits. Observations showed that the app results in a 'break up and rejoin' approach to the construction of the family itinerary in the museum. Individual family members were observed to break away from the family group and rejoin, either following their own personal interests or following other family members' clues - for example, a parent might call a child back to show them something about an exhibit (rejoin), or a parent might follow a child whose attention has been drawn to another exhibit (break away). These patterns had far from a negative impact on family dwell time, which was significantly higher for families who used the app. In fact, use of the app seems to have freed individual family members to follow their own interests [30] while at the same time extending the family's overall interaction with the exhibit.

As this study showed, a mobile app that is designed to meet 
family needs can facilitate family learning in the science museum effectively. Importantly, many families in the study intended to continue using the app after their visit. Such significant post-visit learning and engagement is worth exploring further: a longitudinal study of app user-families could shed light on longerterm impacts on family science learning. Comparisons with families who do not use the app can reveal the magnitude of such impacts. Further research is also needed to investigate differences between first-time, occasional and frequent family visitors in order to nuance how family needs evolve with repeat visits and help us design mobile tools that adapt to these evolving needs. Finally, further research is needed to identify the extent to which the findings presented here can be replicated in other sociocultural, museum and technical contexts.

Like any other visitor group, the family group comprises individuals with distinct needs, abilities and prior experiences. At the same time, the family context means that these individuals share a history of interactions that have, to an extent, shaped these individual contexts. The family interactions in the museum are enmeshed in that history of interactions and, thus, the family visit becomes part of the family identity. Museum experiences can therefore be more than just learning experiences for families, they can become part of what defines a group of people as a family. This study has shown that mobile tools can play an integral part in this process by encouraging more, quality family interactions.

\section{ACKNOWLEDGEMENTS}

W. Suriyakul Na Ayudhya acknowledges support from the National Science Museum, Thailand, through a doctoral studentship. This work has also been partially supported by Thailand's National Electronics and Computer Technology Center. We thank the National Science Museum, Thailand, for granting us permission to undertake this research, and the museum staff and family visitors for their valuable and enthusiastic participation.

\section{REFERENCES}

[1] Falk, J.H. and L.D. Dierking. 2008. Enhancing visitor interaction and learning with mobile technologies. In L. Tallon and K. Walker, Digital technologies and the museum experience: Handheld guides and other media, Alta Mira Press, Walnut Creek, CA, USA. 19-33.

[2] Hsi, S. and H. Fait. 2005. RFID enhances visitors' museum experience at the Exploratorium. Communications of the ACM, 48 (9), 60-65.

[3] Laurillard, D. 2007. Pedagogical forms of mobile learning: framing research questions. In N. Pachler (ed.) Mobile Learning: Towards a research agenda. London: WLE Centre

[4] O'Hara, K., T. Kindberg, M. Glancy, L. Baptista, B. Sukumaran, G. Kahana and J. Rowbotham. 2007. Collecting and sharing location-based content on mobile phones in a zoo visitor experience. Computer Supported Cooperative Work (CSCW), 16(1-2), 11-44.

[5] Pachler, N., B. Bachmair, and J. Cook. 2009. Mobile learning: structures, agency, practices. Springer Science \& Business Media.

[6] Scanlon, E., A. Jones, and J. Waycott. 2005. Mobile technologies: prospects for their use in learning in informal science settings. Journal of Interactive Media in Education, 2 .

[7] Sharples, M., I. Arnedillo-Sánchez, M. Milrad, and G. Vavoula. 2009. Mobile learning: Small devices, big issues. In S. Ludvigsen, N. Balacheff, T. de Jong, A. Lazonder, and S. Barnes (eds.) Technology-enhanced learning: Principles and products. Dordrecht: Springer, 233-249.

[8] Tallon, L. 2008. Introduction: Mobile, digital, and personal. In L. Tallon and K. Walker (eds.) Digital technologies and the museum experience: Handheld guides and other media. Walnut Creek, CA, USA: Alta Mira Press.
[9] Vavoula, G. and M. Sharples. 2009. Meeting the challenges in evaluating mobile learning: a 3-level evaluation framework. International Journal of Mobile and Blended Learning, 1, 54-75.

[10] Vavoula, G., M. Sharples, E. Scanlon, P. Lonsdale, and A. Jones. 2005. Report on literature on mobile learning, science and collaborative acitivity. https://telearn.archives-ouvertes.fr/hal-00190175/document.

[11] Sharples, M., D. Corlett, and O. Westmancott. 2002. The design and implementation of a mobile learning resource. Personal and Ubiquitous computing. 6 (3) 220-234.

[12] Ash, D. 2003. Dialogic inquiry in life science conversations of family groups in a museum. Journal of Research in Science Teaching. 40 (2) 138-162.

[13] Blud, L.M. 1990. Social interaction and learning among family groups visiting a museum. Museum Management and Curatorship. 9 (1) 43-51.

[14] Borun, M., M. Chambers, and A. Cleghorn. 1996. Families are learning in science museums. Curator: The Museum Journal. 39 (2) 123-138.

[15] Borun, M., M.B. Chambers, J. Dritsas, and J.I. Johnson. 1997. Enhancing family learning through exhibits. Curator: The Museum Journal, 40(4), 279-295.

[16] Borun, M., A. Cleghom, and C. Garfield. 1995. Family learning in museums: A bibliographic review. Curator: The Museum Journal. 38 (4) 262-270.

[17] Diamond, J. 1986. The behavior of family groups in science museums. Curator: The Museum Journal. 29 (2), 139-154.

[18] Dierking, L.D., J.J. Luke, K.A. Foat and L. Adelman. 2001. The family and free-choice learning. Museum News -Washington, 80(6), 38-43.

[19] Ellenbogen, K.M., J.J. Luke, and L.D. Dierking. 2004. Family learning research in museums: An emerging disciplinary matrix? Science Education. $\mathbf{8 8}(\mathrm{S} 1)$.

[20] Ellenbogen, K., Luke, J.J. and Dierking, L.D., 2007. Family learning in museums: Perspectives on a decade of research. In Falk, J.H., Dierking, L.D. and Foutz, S. (eds.). In principle, in practice: Museums as learning institutions. Rowman Altamira, 17-30.

[21] Falk, J.H. and L.D. Dierking. 1992. The Museum Experience. Ann Arbor, MI: Whalesback Books.

[22] Falk, J.H. and L.D. Dierking. 2000. Learning from museums: Visitor experiences and the making of meaning. Altamira Press.

[23] Hike, D. 1989. The family as a learning system: An observational study of families in museums. Marriage \& family review, 13(3-4) 101-129.

[24] McManus, P. 1994. Families in museums. In Miles, R. and Zavala, L. (eds.). Towards the museum of the future: new European perspectives. Routledge, 81-97.

[25] Bruner, J.S., 2009. Actual minds, possible worlds. Harvard University Press.

[26] Vygotsky, L.S. 1980. Mind in society: The development of higher psychological processes. Harvard university press.

[27] Borun, M. 2002. Object-based learning and family groups. In Paris, S.G. (ed.) Perspectives on object-centered learning in museums. Routledge, 245-260.

[28] Anderson, D., M. Storksdieck, and M. Spock, Understanding the long-term impacts of museum experiences. In Falk, J.H., Dierking, L.D. and Foutz, S. (eds.). In principle, in practice: Museums as learning institutions. Rowman Altamira, 197-215.

[29] Stevenson, J. 1991. The long-term impact of interactive exhibits. International Journal of Science Education, 13(5) 521-531.

[30] Dierking, L.D. 1989. The family museum experience: Implications from research. Journal of Museum Education, 14(2) 9-11.

[31] Dierking, L.D. and J.H. Falk. 1994. Family behavior and learning in informal science settings: A review of the research. Science Education, 78(1), 57-72.

[32] Falk, J.H., T. Moussouri, and D. Coulson. 1998. The effect of visitors' agendas on museum learning. Curator: The Museum Journal, 41(2), 107120 .

[33] Henderson, A., S. Watts, and H. Erickson. 2000. Learning how they learn: the family in the museum. Museum News - Washington, 79(6), 40-40.

[34] Reynolds, R., C. Speight, and K. Walker. 2009. Bridging formal and informal learning using mobile digital museum trails. 3rd WLE Mobile Learning Symposium: Mobile Learning Cultures across Education, Work and Leisure. London, UK

[35] Brooke, J. 2013. SUS: a retrospective. Journal of usability studies. 8(2), 2940.

[36] Hooper-Greenhill, E., Dodd, J., Moussouri, T., Jones, C., Pickford, C., Herman, C., Morrison, M., Vincent, J. and Toon, R. 2003. Measuring the outcomes and impact of learning in museums, archives and libraries: the Learning Impact Research Project end of project paper.

[37] Glasser, B. and A. Strauss. 1967. The Discovery of Grounded Theory: Strategies for Qualitative Research. Adline De Gruyter. New York.

[38] Bitgood, S. 2010. An attention-value model of museum visitors. Center for Advancement of Informal Science Education: Washington, DC, USA.

[39] Kortum, P.T. and A. Bangor. 2013. Usability ratings for everyday products measured with the System Usability Scale. International Journal of HumanComputer Interaction. 29(2), 67-76. 